\title{
Fair-minded critical thinking: Towards a reconciliation of the self and the other
}

\author{
M. Adeyinka Akapo* and J. Tunde Akande \\ Department of Philosophy, University of Abuja. Abuja, Nigeria. \\ *Corresponding author. Email: addayinka@gmail.com; Tel: +234 8056554644.
}

Copyright (C) 2021 Akapo and Akande. This article remains permanently open access under the terms of the Creative Commons Attribution License $\underline{4.0}$, which permits unrestricted use, distribution, and reproduction in any medium, provided the original work is properly cited.

Received 23rd September, 2021; Accepted 16th October, 2021

\begin{abstract}
This work examines the role which fair-minded critical thinking can play in the attempt to reconcile the self with the other. It argues that much of the problems encountered in human relations arise from either uncritical thinking or unfair-minded critical thinking. This happens as a result of the enthronement of both the individual and social ego, on account of the weakening of the fair-minded critical thinking faculty on the one hand, and the strengthening of that of the unfair-minded critical thinking, on the other. The overall result of this is the lack of peace and cooperation among men as well as between man and nature. This work, therefore, identifies fair-minded critical thinking as a missing link in previous attempts to reconcile the self with the other and recommends its cultivation as a veritable tool for the achievement of any meaningful measure of success in such attempts at reconciliation. It also shows how much humanity stands to benefit from the conscious and deliberate cultivation of the principles of fair-mindedness in all relations between the self and the other. The work adopts critical analysis in its discourse.
\end{abstract}

Keywords: Conflict, disagreement, humanity, revolution, unfair-mindedness, violent conflict.

\section{INTRODUCTION}

Contenders in every conflict situation can be analyzed into the self and the other. While the self is the subject, the other is the object, although the subject in one instance can become the object in another instance and vice versa. Conflict is a common feature of human life. It is a natural consequence of the human need to interact and live in society. As man lives in society, he necessarily interacts. In the course of interaction, conflicts arise. This goes to show, therefore, that conflict is always between a self and another. The causes of conflict include social, intellectual or ideological, political, economic, religious, value orientation, institutional causes and so on.

While conflict may be seen as a necessary lubricant of human relations, it is obviously not the violent form of it that is. The challenge then is how to avoid violent conflicts by reconciling the self and the other as the power and influence of logic and careful reasoning are being applied towards destructive and selfish ends. This is a result of the dire need to define the self into some sort of significance that has dangerously and erroneously made us arrive at a definition of the other (person or people) as less valuable than ourselves. In essence, we project an idea of what we would rather not be, as what the other person is.

We must understand therefore, that the person we are capable of harming can harm us too. The person we are capable of taking advantage of or depriving can take advantage of and deprive us too. The person we think we can kill, also is capable of killing us. We should stop and think, that what if the person we are acting against was to carry out our exact intention or action against us? Hobbs hinted us that, "...the only true equality among men is their power to kill each other" (Hobbes, 2018). Yes, the power to kill each other is a description of the highest harm we can inflict on each other. This is because we are all capable of doing all manner of things to each other or acquiring the capacity to do so. But the key to the rusted social lock of virtue is creating a mutually dignifying image of our self and the other, through a critical understanding of the fact that the self in isolation is incapable of achieving and enjoying or even being anything worthwhile. We need 
Integ. J. Arts and Human.

each other to form sane institutions and societies. And this need for each other, presupposes therefore, that there is interdependence between the self and the other. Such that, for the self to be itself, there must be an other and that other does not deserve less consideration, attention or dignity than the self. This is one of the many insights which the principles of fair-minded critical thinking present to us.

\section{OTHER ATTEMPTS TO RECONCILE THE SELF WITH THE OTHER}

Oyeshile (2005) took to the existentialist views of Heidegger and his concept of Dasein, Sartre and his notion of Being and Choice, Bauber and his view of the Interhuman and Gabriel Marcel and the Problem of Mystery, to reconcile the self and the other.

$\mathrm{He}$ admitted that conflict, especially at the interpersonal level is inevitable. For him, where diverse groups of people live, conflict is bound to be present (Oyeshile, 2005). This aligns with Unah (2000) who believed agreeably, that conflicts generally do not occur in a "Robinson Crusoe situation" i.e., in isolation. Rather, they occur fundamentally from social relatedness. So far as we are human beings living in a human society, conflicts cannot but occur.

Also, and very important are the social contract theorists' attempt to reconcile the self and the other. Even as they did not expressly state that they were attempting a reconciliation of the self and the other, their views were attempts to present the social contract theories to reconcile man in society. These views are the views of the social contract theorists such as Hobbes (1991), Locke (1960) and Appadorai (1968). They observed that it was the possession of rights and the will to uphold or use it against others that was the issue, and they believed that submission of such rights was the solution to the problems in the state of nature.

There were also some religious attempts at reconciliation, such as those of Hinduism that prescribes Yoga, which is a way to God. All the forms of yoga are directed towards reducing the effect and control of the ego and replace them with the God consciousness (Pojman, 2006).

An Islamic perspective can be seen in the summation of the prophet's teachings as presented by Khan (2015) that we should not wish for confrontation with our enemies; instead, we should always ask for peace from God. This means that even when they have enemies, Muslims are not allowed to take the course of confrontation. They must rather seek the way of avoidance.

From the Christian perspective, the teaching of Christ is that we should love both the lord and our neighbors. "Love the Lord your God with all your heart and with all your soul and with all your mind and with all your strength. The second is this: 'Love your neighbor as yourself. There is no commandment greater than these" (Mark 12:30-31).
Also, from the humanist angle is the Ubuntu. A humanist attempt at reconciliation. Ntamushobora (2012) applied the humanistic implication in Ubuntu to reconcile the self and the other. Trying to give reasons for the application of Ubuntu, his paper presents a brief development of the theology of Ubuntu for the prevention of conflicts and violence and the promotion of reconciliation among people of different tribes, races, religions and social status. Also, it proposes that the theology of Ubuntu, namely, that "a person is a person through other persons" if developed as the model of the unity and diversity of the Trinity, could offer a remedy for social, religious and economic challenges threatening the beauty of unity in diversity and could lead to flourishing of individuals and their communities (Ntamushobora, 2012: 1-3).

Socrates and Plato believed that the right education instills the right attitude in people. For Plato, like Socrates, "knowledge is virtue and ignorance is vice." The implication of this is that the things we do are either as right or wrong as our level of knowledge or ignorance. Socrates believed that "virtue could be known, though he himself did not profess to know it. He also thought that anyone who knows what virtue is will necessarily act virtuously. Those who act badly, therefore, do so only because they are ignorant of, or mistaken about the real nature of virtue" (Singer, 2018). In the same line, for Plato whose view of education is a path to virtuous knowledge and whose knowledge is a path to justice; knowledge and education can be understood to be more about balancing the three elements that make up a person as a path to justice and proper conduct. Singer remarks, according to Plato:

... justice exists in the individual when the three elements of the soul-intellect, emotion, and desire act in harmony with each other. The unjust person lives in an unsatisfactory state of internal discord, trying always to overcome the discomfort of unsatisfied desire but never achieving anything better than the mere absence of want. The soul of the just person, on the other hand, is harmoniously ordered under the governance of reason, and the just person derives truly satisfying enjoyment from the pursuit of knowledge. Plato remarks that the highest pleasure, in fact, comes from intellectual speculation. ... In summary, then, Plato asserts that we should act justly because in doing so we are "at one with ourselves and with the gods (Singer, 2018).

From this, we can see that education is not about developing the intellect alone, but training the will as well. We can also see that virtue and oneness are important outcomes of a proper education in the view of Plato and Socrates as no law, according to Plato, is greater than knowledge (Omoregbe, 2007). I would like to think that a person of proper conduct needs no laws and those who lack proper conduct will not be hindered by laws. What then may be the ultimate personal guide? I would say, fairmindedness. In a case where a person chooses to misuse 
the understanding of laws and benefits of education for selfish interest, we would see that the system of education that produced such intellect has failed. This failure I will insist is as a result of the lack of fair-mindedness.

Applying the categorical imperative of Kant (2018), that we should "act only according to that maxim by which you can at the same time will that it should become a universal law" which is usually regarded as an objective rationally unconditional principle regardless of our natural tendency towards the contrary. Anything we do, is justified as either rational or irrational based on its conformity to or violation of this principle. Johnson (2016) sees it as the presence of this self-governing reason in each person that Kant thought offered decisive grounds for viewing each as possessing of equal worth and deserving of equal respect. This is offered as a moral compass for assessment of deeds among the self and the other. Whatever thought or action a person directs towards another, would he be willing that that becomes a universal standard for thought and action, given the same condition? And if it is so made, what will be the outcome? Here, we can see an attempt to reconcile the self with the other by a proposition of best practice that is willed to become a universal law or standard for action.

In the Feministic view of De Beauvoir (1949), we will see that she undertook to trace the historical, biological, psychological and evolutional origin of the current distasteful state of relation between the male and female gender. According to her, the fact is that today (in her days and even worse now) neither men nor women are satisfied with each other. But the question is to know whether there is an original curse that condemns them to rend each other or whether the conflicts in which they are opposed merely mark a transitional moment in human history (De Beauvoir, 1949). After tracing the origin of the problem between man and woman, she opined that "it is vain to apportion praise and blame. The truth is that if the vicious circle is so hard to break, it is because the two sexes are each the victim at once of the other and of itself' (De Beauvoir, 1949). And the solution she offered was respect and reciprocity of being the self and the other for and to each other (De Beauvoir, 1949).

Fundamentally, all of these would not be possible without both parties having at the back of their minds and as a functional guide, the principles of fair-mindedness. Yes, we are all humans and are affected by the limitations of what it means to be so. People will come up with different excuses and justification to not be responsible human beings and adopt any proffered solution except of course they first are fair-minded. This, for us, explains why even as yet many of the previous attempts have proven to be popular, they have been well debated and in fact, they have formed bases for several revolutions over time. Yet, the problem between the self and the other has neither been minimized nor eradicated. It has only been modified over time. People are developing more dangerous and secretive ways of destroying themselves in the world today. Not because history and historical intellection has not given us enough tools and reasons to improve and or change. But it is rather because people for one reason or the other get ever more unfair-minded.

\section{WHAT IS FAIR-MINDED CRITICAL THINKING?}

According to Al-Qahtani and Al-Nafisi (2017), of the many traits of a disciplined mind, fair mindedness is one. As they rightly put it, "critical thinking involves basic intellectual skills, but these skills can be used to serve two incompatible ends: self-centeredness and fairmindedness" (Al-Qahtani and Al-Nafisi, 2017). They believe that a strong sense of critical thinking strives to be fair-minded and uses thinking in a responsible manner. To be a good critical thinker, one must strive to be fair in the use of the mind in all human endeavors especially as regards interpretation of information, interaction with others and in passing judgment.

Paul (2011) shared this view when he wrote that to think critically in the strong sense requires that we develop fairmindedness at the same time that we learn basic critical thinking skills and, thus, begin to "practice" fairmindedness in our thinking. If we do, we avoid using our skills to gain unfair advantage over others. We treat all thinking by the same high standards. We expect good reasoning from those who support us as well as those who oppose us. We subject our own reasoning to the same criteria we apply to reasoning to which we are unsympathetic. We question our own purposes, evidence, conclusions, implications, and point of view with the same vigor we question those of others (Al-Qahtani and AlNafisi, 2017).

As such, it will suffice to hold the view that to be fairminded involves a disposition to address all perspectives without bias and prejudice. It involves the understanding that we have the natural tendency to think or act out of certain biases either for our own benefit or that of those to whom we are attached and against those whom we stand. Fair-mindedness involves wanting justice for all, regardless of the implication of such to one's interest. It involves setting and having the same standard for the evaluation of the self, the self's interest and those of others.

It makes sense then that according to Paul, "fairmindedness requires us to be, simultaneously, intellectually humble, intellectually courageous, intellectually empathetic, intellectually honest, intellectually perseverant, confident in reason (to be persuaded by good reasoning), and intellectually autonomous. Unless this family of traits functions in an integrated constellation, fair-mindedness is incomplete" (Paul, 2011).

Furthermore, Diestler and Mahy (2010) observed that fair-mindedness addresses two main issues, which are Ethnocentrism and Egocentrism. Olena shares this view when he called our attention to the fact that there is a tendency in human nature arising from a childhood 
Integ. J. Arts and Human.

predisposition to consider ourselves as the center of the universe. And that this self-centered way of treating issues has historically clouded our science, our interpretation of events in the world, our view of other cultures and our belief systems. This cloud has created ethnocentrisms or sociocentrism and egocentrism (Olena, 2017).

Ethnocentrism which sometimes manifests and is referred to as (sociocentrism) is the tendency to give primacy to one's own race, culture or group, based on the belief that such race, culture or group is superior to all others (Olena, 2017).

Egocentrism is "a tendency to view everything else in relationship to oneself' (Olena, 2017: 6). It is a situation wherein one's desires, values and beliefs are often uncritically used as the norm of all judgment and experience. Seen as the individual version of ethnocentrism, egocentrism manifests when an individual sees everything in relation to himself.

Egocentrism and ethnocentrism as such are traits that make fair-minded critical thinking difficult and almost impossible. But luckily for us, Olena (2017), just like Diestler and Mahy (2010) noted some traits of fairmindedness that can be applied to counter these two mental debilities. These traits are:

1. A respect for people whose ethnicity and tradition are different from our own.

2. A willingness to hear and understand the other person's viewpoint.

3. An openness to change when new information or insight warrants that change.

4. To reconcile the basic defense mechanisms we use to distort reality to deceive others and ourselves.

5. To recognize areas where we, for whatever reason, have trouble being rational.

6. To understand and have empathy for someone else's viewpoint.

\section{RECONCILING THE SELF WITH THE OTHER}

A fair-minded person, who wants to truly define himself and weigh himself in relation to the other, ought to ask, what will life be like without the other? Better still, what shall it profit a self, to gain the whole world and be alone?

In the process of self-definition and actualization, we must understand that as Simone de Beauvoir rightly said, the refusal to pose oneself as the subject, unique and absolute, requires great self-denial (De Beauvoir, 1949). Yes, it is a serious self-denial of food for one's ego. Yet, this denial is very necessary. We must understand that the starvation of others is not the best way for us to be truly satisfied, if it is a way at all. The negation or reduction of others is not a good way for us to be significant, even as it is a common way these days. We will always only amount to exactly whatever we are worth on the socio-economic or political scale and this makes it necessary for us to be humble. But this our characteristic habit of inhibiting the progress and development or actualization of others out of intellectual arrogance, so that we can remain significant forever is not the best. We must understand that, as the Yoruba's say, "the sky is big enough for birds to fly without their feathers touching each other." As such, we do not, as social birds, have to engage in the joke of pulling out each other's feathers so we can define ourselves as feathery and others as featherless. An equal playing ground and a general progression will not hurt anyone, instead, it will relieve the pain and struggle of many. We must begin to see and appreciate the values of our commonness and key into it, for the general good.

Some people are of the view that it is natural to have an unbalanced social structure, but a close and fair-minded outlook will help us to understand that, if we have evolved as some people believe, from a crude 'state of nature' to this seeming level of refinement, we should agree also that the imbalance in nature is not for inferiority or superiority's sake, but rather for peculiarity, diversity and complementarity's sake. It is on the backdrop of this that Lamm (1996) presented the view that we are made for cooperation, like feet, like hands, like eyelids, like the row of the upper and lower teeth. To be different but to function together and achieve great good.

Also, it is the lack of fair-minded critical thinking especially intellectual integrity that serves as the foundation for the feeling of superiority complex. This is because there is a double standard with which the self and its actions are evaluated and justified against those of others when our intellectual empathy is either dead or in coma. The absence of fair-mindedness is the reason why anyone would critically nurtures superiority complex. Superiority complex being a Siamese twin of intellectual arrogance. Just as the existence of superiority complex is the fertile soil for violence stemming from the application of force or the need for resistance. Violence here is meant in the sense of the critical stoic Aurelius when he spoke of the soul doing violence to the self as that:

The soul of man does violence to itself, first of all, when it becomes an abscess and, as it were, a tumor on the universe, so far as it can. For to be vexed at anything which happens is a separation of ourselves from nature, in some part of which the natures of all other things are contained. In the next place, the soul does violence to itself when it turns away from any man, or even moves towards him with the intention of injuring, such as are the souls of those who are angry. In the third place, the soul does violence to itself when it is overpowered by pleasure or by pain. Fourthly, when it plays a part, and does or says anything insincerely and untruly. Fifthly, when it allows any act of its own and any movement to be without an aim, and does anything thoughtlessly and without considering what it is, it being right that even the smallest things be done with reference to an end; and the end of rational animals is to follow the reason... (Aurelius, 167 ACE). 
It makes sense therefore, to believe that the least that can happen is good, if and when we all treat each other fairly and when we work together fair-mindedly without needing to be more or less than we are. We are just what we are. Derogating or reducing another or ourselves is more or less an act of violence against humanity and nature as a whole.

Even when we think we have rights, we must understand when debating our rights, that one does not fully understand or have a right to his right until he or she understands and maintains his or her responsibility to others and their rights.

In any worthwhile debates, fair-mindedness provides us with the disposition to be informed about the other person's point of view, so as to properly understand it before we either accept or reject it. It also involves, a preparedness to rationally defend our own standpoint as well as develop empathy, as opposed to the emotional defense that tempts us to rather seek out the flaws in our opponents' arguments without good listening to understand and acknowledge his or her topically strong point for better information.

"Knowledge is virtue and ignorance is vice," Said Plato. Looking at this statement, you will see that we need information to truly know anything properly enough to make decisions or take the right actions. As such, a fairminded person begins by telling himself the truth about the limits of his or her knowledge over certain issues and seek to know more by developing an open mind, thereby leaving no room for absolutist stand but for better disposition towards humility.

Applying fair-mindedness saves us from the dangerous implications of tags, identities and general assumptions. It brings us to the understanding that good and evil are human tendencies rather than a racial or cultural trait of any people. As such, one can either enjoy or suffer from any of many social distinctions.

Of course, there could be a thesis and antithesis about anything, but a fair-minded person will hold a point of probability in an attempt to stand in synthesis so as to be safe in the case of either. Take for example, a thesis that (Hausa people are dangerous as friends). The antithesis would be that (Hausa people are not dangerous as friends). One will see that, if fair-minded critical thinking is applied here, a person who wants to associate with a Hausa person and probably make him a friend might suffer the danger of bringing a bad person close. Yet he is also not spared the possibility of pushing a good person away. Therefore, the synthetic thing to do is to understand that most human beings have the tendency for either or both good and evil. This will lead the person to go ahead and associate but carefully and fair-mindedly with anyone he is trying to associate with, be they Hausa or not. By so doing, over time, the proverbial palm wine keg will show where the rope ought to be tied.

In marriages these days, we find out that couples do not have it going smooth in their relationship with each other.
Those who are conversant with trends about couples in today's world would have heard the rampant cases of wives killing their abusive husbands. Divorces, and separations are not strange anymore either because the husband, wife or both of them are being uncritical. The unbearable pride and arrogance of one or both partners make the marriage fail simply because they are being either uncritical, or critically unfair-minded. When couples begin to look at and see each other in a complementary manner, showing mutual intellectual empathy, humility, courage, confidence in reason, and so on in their marriages, they will both see that they are meant to stay together and deal with their issues, not to see each other as opponents and deal with each other to the pleasure of the problems. Fair-mindedness enables them to mutually dignify themselves and grow in the strength of understanding each other. It requires dropping off unhealthy doctrines and ideologies that encourage one or both to act against one another.

\section{EVALUATION}

Having taken a look at other attempts to reconcile the self with the other, this work has been able to show the missing link between such attempts and the desired results to be that, it is not that such attempts were not plausible, but that fair-mindedness is missing in the minds of those who would interpret and apply those principles in societies. It has also shown, taking a look at the idea of the self and the other, how fair-mindedness is missing in important aspects of our lives ranging from socio-political to economic, to marital and environmental aspects of our social and intellectual structure. Furthermore, it has shown what fair-minded critical thinking is and what it is about, ranging from its principles and inhibiting traits down to the antidotes to such inhibiting traits. Finally, it has earlier in this chapter shown how fair-minded critical thinking can be applied to basic related aspects of our lives in an attempt to present it as a veritable tool for the reconciliation of the self with the other.

Of course, it is not easy to apply all the principles of fairmindedness to the letter, but if we were to give an assessment of a person's conduct in relation to fairmindedness, I would check the level of efforts that is put towards a genuine avoidance of conflict and violence with and to others. When we run the race of life and come in full circle, we will see that true satisfaction and peace for the self is in the wellbeing of the other(s) and our contribution to that wellbeing. As the Yorubas do say, "eating together is not so sweet when one person is lacking". This presupposes that there is a spirit of solidarity that makes enjoyment more pleasurable when people share from mutual abundance. The absence of mutual abundance in the world today is what fertilizes our environment for violence. Violence done, either in the protection of possessions or possession of protection. 
People doing despicable things to each other to have what they desire or to protect what they have. This, I believe, can be drastically reduced if not totally eradicated if we all consciously put in genuine efforts towards developing a fair-minded rational mind where every member of the society contributes their best and take just what they need. Of course, this would remind us of the Marxist ideal community after the revolution (communism). We will see though that Marx expected that all would just act right in a communist society, but I believe that there would be no better police in such society and the mind of people, than fair-mindedness. It would serve as the soul to the body of all ethical principles and laws if there be a need for any.

\section{CONCLUSION}

As a means to make people develop the invaluable trait of fair-mindedness, It would be suggested that fairmindedness be borne in mind when designing sociopolitical, economic, educational and environmental and other policies, while it is also imbibed into the body and spirit of academic curriculums for all disciplines. This is because, any form of knowledge could be dangerous in the hands of anyone without fair-mindedness. The evidences to this would be the lots of unfair-minded critical thinkers.

We would have lost all the essences in the struggle of life when we continue to apply ourselves in violence against each other and discriminating or separating from each other according to irrelevant identities or designations that we hide under. Depriving both the self and the other of mutual trust, justice, peace, love and happiness that we all deserve. Diestler and Mahy remind us that "When we acknowledge how intimately we are connected to others, we cannot remain superior. Such an attitude of superiority is harmful to the dialogue that must take place in order to begin to resolve the social, economic, political and environmental concerns that affects our increasingly interdependent world (Diestler and Mahy, 2010). The violence we commit when we divide ourselves turns our general wellbeing into a mirage that we keep aspiring towards but never actually attain.

It will make sense, therefore, to see the world as a whole. To refuse superiority between men and women and between blacks and whites as we immediately dissolve and unite in being human. To refuse to see superiority between humans and animals as well as animals and plants, since we all have an organic relationship and share in the fact that we are beings.

As such, it suffices to note that it is important to see the human being in others, to have intellectual empathy (an understanding that people are not perfect and their imperfection is not an excuse to treat them with indignity), intellectual humility (understanding that you are not perfect and that others may be capable where you are not, just as you might be where they are not), intellectual perseverance (a readiness to tolerate and put up with the assortments of mentalities, choices and decision that characterize the world and your immediate environment while you consciously put up your best behavior towards all and sundry), intellectual courage (a readiness to defend yourself from others and others from yourself, by standing up both for yourself and others), intellectual integrity (a readiness to refuse to compromise intellectual standards according to convenience and sentiment, being true to who you are and having genuine inclination to improve), intellectual autonomy (having a mind of your own), confidence in reason (believing in the result of honest and sound reasoning regardless of who or where it is coming from and whether or not it agrees with your previously held views) and a single standard for examining and interrogating the self and others.

If we want a better world as we claim, the solution does not lie in selfish pursuit of knowledge while others are ignorant, it does not lie in the selfish pursuit of wealth while other are in poverty, it does not lie in the getting or having anything good for the self that the other does not have. It does not lie in seeing others as mere means to an end, it does not lie in our increasing social competition that is driving us crazily into the need to outshine each other. It lies in mutual fair-minded consciousness, because, where one person is fair-minded and the other is not, it makes virtue difficult to apply, but it ought to be applied anyway. For this reason, borrowing De Beauvoir's expression, that "the garden must be planted all at once" is suggested. We must deliberately and consciously move to preserve and better each other. We should know that the one or the self is nothing worthwhile without the other. We must bring members of society to understand through a careful system of social, academic and environmental education, that together, we share in and play significant roles in the existence of each other, and that that role is not one of superiority or inferiority but rather complementarity.

\section{REFERENCES}

Al-Qahtani, N., \& Al-nafisi, B. (2017). Chapter 3, Becoming a fairminded Thinker. Retrieved 13th August 2017 from https://slideplayer.com/slide/12368134/

Appadorai, A. (1968). The substance of politics. Oxford: Oxford University Press. Pp. 27-28.

Aurelius, M. (167). The meditations. Written 167 A.C.E. Book two, translated by George Long. Retrieved 1st October, 2017 from http://classics.mit.edu/Antoninus/meditations.2.two.html.

De Beauvoir, S. (1949). The second sex. E-Go Library. Retrieved from http://www.Free-eBooks.net.

Diestler, S., \& Mahy, C. (2010). Becoming a critical thinker: A user friendly manual. Canadian Edition. Toronto: Canada; Pearson Education. p. 323.

Hobbes, T. (1991). The Leviathan. R. Tuck (ed.). Cambridge University Press. p. 120

Hobbes, T. (2018). In: John Edward Bowle (ed.). Political philosophy. Encyclopedia Britannica. Ultimate Reference Suite. (Chicago: Encyclopedia Britannica).

Johnson, R. (2016). Kant's Moral Philosophy. Stanford Encyclopedia of Philosophy. Retrieved from https://plato. 
stanford.edu/entries/kant-moral/

Kant, I. (2018). Categorical imperative. Ultimate Reference Suite. Chicago: Encyclopedia Britannic.

Khan M. W. (2015). The concept of peace in Islam. Retrieved January 24, 2018 from http://cpsglobal.org/content/conceptpeace-islam.

Lamm, R. C. (1996). Humanities in Western culture: A search for human values, Fourth Edition, Brief Edition, McGraw-Hill, p. 145.

Locke, J. (1960). Two treatises of government. P. Laslett (ed.). Cambridge: Cambridge university press. p. 367.

Mark (12:30-31). The Holy Bible.

Ntamushobora, F. (2012), The philosophical presuppositions of Ubuntu and its theological implications-- for reconciliation. Daystar University Centre for Research, Publications and Consultancy Working, Paper Series. CRPC Working Paper Number DU/2012/007. Pp. 1-3.

Olena, D. (2017). Fair-Mindedness: Chapter 9, Introduction to critical reasoning. Pp. 3-6. Retrieved 13th August 2017 from https://nanopdf.com/download/fair-mindedness_pdf.
Omoregbe, J. (2007). Social-political philosophy and international relations: A systematic and historical study, Vol. 1. Joja Educational Research Publishers Limited, Ikeja, Lagos: Nigeria. p. 26.

Oyeshile, O. A. (2005). Reconciling the self with the other: An existentialist perspective on the management of ethnic conflicts in Africa. Ibadan: Nigeria; Hope Publications.

Paul, R. (2011). Chapter 1, Becoming a fair-minded thinker. P. 4: M01_PAUL0917_03_SE_C01. indd 2/21/11 5:11 PM.

Pojman, L. P. (2006). Who are we? Theories of Human Nature. Oxford University Press. p. 90.

Singer, Peter. (2018). Ethics. Encyclopedia Britannica. Ultimate Reference Suite. Chicago: Encyclopedia Britannica.

Unah, J. I. (2000). Difficult decision situation: A phenomenological ontology of crisis management. Tymienieka A. T. (ed). Anelecta Hursserlianan, p. 237. 